\title{
Novel risk factors for primary prevention of oesophageal carcinoma: a case-control study from Sri Lanka
}

\author{
Ishanka Ayeshwari Talagala ${ }^{1 *}$ (D) Metthananda Nawarathne ${ }^{2}$ and Carukshi Arambepola ${ }^{3}$
}

\begin{abstract}
Background: Oesophageal carcinoma (OC) is one of the leading cancers in Sri Lanka. Its increasing incidence despite the implementation of various preventive activities addressing the conventional risk factors indicates the possibility of the existence of novel, country-specific risk factors. Thus, the identification of novel risk factors of OC specific to Sri Lanka is crucial for implementation of primary prevention activities.

Methods: A case-control study was conducted among 49 incident cases of OC recruited from the National Cancer Institute, Maharagama using a non-probability sampling method, and unmatched hospital controls $(n=196)$ excluded of having OC recruited from the endoscopy unit of the National Hospital of Sri Lanka. Data were collected using an interviewer administered questionnaire. Risk factors for OC were assessed by odds ratio (OR) with $95 \%$ confidence interval $(\mathrm{Cl})$. The risk factors were adjusted for possible confounding by logistic regression analysis.

Results: Of the study population, OC was common among males (69\%) and the majority presented with squamous cell carcinoma (65\%) at late stages (Stage IV: 45\%; Stage III: 37\%). Following adjusting for confounders, the risk factor profile for $\mathrm{OC}$ included; age > 65 years $(\mathrm{OR}=4.0 ; 95 \% \mathrm{Cl}: 1.2-14.2)$; family history of cancer $(\mathrm{OR}=5.04 ; 95 \% \mathrm{Cl}$ : 1.3-19.0); sub-optimal consumption of dietary fibre $(\mathrm{OR}=3.58 ; 95 \% \mathrm{Cl}$ : 1.1-12.3); sub-optimal consumption of anti-oxidants $(\mathrm{OR}=7.0 ; 95 \% \mathrm{Cl}: 2.2-22.5)$; over-consumption of deep fried food (OR=6.68; 95\% Cl:2.0-22.6); 'high risk' alcohol drinking (OR $=11.7 ; 95 \% \mathrm{Cl}$ : 2.8-49.4); betel quid chewing ( $\mathrm{OR}=6.1 ; 95 \% \mathrm{Cl}$ : 2.0, 20.0); 'low' lifetime total sports and exercise activities (MET hours/week/year) $(\mathrm{OR}=5.83 ; 95 \% \mathrm{Cl}$ : 1.5-23.0); agrochemicals exposure $(\mathrm{OR}=6.57 ; 95 \%$ Cl: 1.4-30.3); pipe-borne drinking water $(\mathrm{OR}=5.62 ; 95 \% \mathrm{Cl}: 1.7-18.9)$ and radiation exposure (OR=4.64; 95\% Cl: 1.4-15.5). Significant effect modifications were seen between betel quid chewing and male sex $(p=0.01)$ and between ever exposure to radiation and age over 65 years $(p=0.04)$.
\end{abstract}

Conclusions: Risk profile for $\mathrm{OC}$ includes novel yet modifiable risk factors in relation to diet, occupation, environment and health. Primary prevention should target these to combat OC in Sri Lanka.

Keywords: Oesophageal carcinoma, Novel risk factors, Primary prevention, Sri Lanka

\section{Background}

Cancer plays a major role in the global burden of diseases. In particular, oesophageal carcinoma signifies a disease of public health importance as the eighth commonest cancer in the world [1]. Despite the recent advances in clinical management [2], it shows poor prognosis with only $5-10 \%$ five-year survival, contributing to all cancer deaths by $6 \%$

\footnotetext{
* Correspondence: drishanka@gmail.com

${ }^{1}$ National Programme for prevention and control of non-communicable diseases; Ministry of Health, Nutrition and Indigenous Medicine, Colombo, Sri Lanka

Full list of author information is available at the end of the article
}

and assuming the sixth leading cause of cancer deaths worldwide [1]. It is also the sixth leading cause for cancer related years of life lost (YLL) in the world [3] with YLL accounting for $97 \%$ of the total disability adjusted life years (DALYs) [4]. More importantly, oesophageal cancer has been identified as a virulent tumour in developing countries; assuming the fourth place among all cancers, comprising $81 \%$ of all newly diagnosed oesophageal carcinoma cases in the world, and 84\% of DALYs attributable to cancers occurring in the developing countries [4]. According to the latest statistics, the highest incidence has been

(c) The Author(s). 2018 Open Access This article is distributed under the terms of the Creative Commons Attribution 4.0 International License (http://creativecommons.org/licenses/by/4.0/), which permits unrestricted use, distribution, and reproduction in any medium, provided you give appropriate credit to the original author(s) and the source, provide a link to the Creative Commons license, and indicate if changes were made. The Creative Commons Public Domain Dedication waiver (http://creativecommons.org/publicdomain/zero/1.0/) applies to the data made available in this article, unless otherwise stated. 
reported from Asia and Africa [1], thus necessitating prompt action for prevention in these regions.

Sri Lanka, a developing country located in South Asia reports oesophageal cancer as the third commonest cancer following breast cancer and cancers of the oral cavity [5]. It has continued to be the third commonest cancer among males and fifth commonest among females [5]. With the middle-age population being more vulnerable to this disease, it has affected the national labour force $[5,6]$. Also, with cancer care being predominantly provided by the state, and increasingly financed by out of pocket spending [7], it poses a great impact on the economy of individuals, households as well as the country.

Considering the importance of combating cancers in the world including oesophageal carcinoma, 'World Cancer Declaration' endorsed by the World Cancer Congress in 2010 calls upon all the member states of the World Health Organization to implement nine immediate actions including policy development, cancer prevention and early detection by strengthening health systems [8]. The National policy and strategic framework on cancer prevention and control, Sri Lanka - 2015, thus identifies "Ensuring primary prevention of cancers by addressing risk factors and determinants by improved public awareness and empowerment" as a policy objective and implement various activities in order to prevent any type of cancer by combating its risk factors [9]. However, despite oesophageal carcinoma being one of the leading cancers in Sri Lanka, there is no specific prevention programme implemented against it in the country.

Prevention of oesophageal carcinoma is based on the principles of primary prevention on reducing the burden of its risk factors. The underlying causes of oesophageal carcinoma are multi-factorial. As with other chronic non-communicable diseases, the commonly known risk factors are related to one's non-modifiable demographic (e.g. older age, male sex, genetic predisposition $[1,10])$, socio-economic and clinical status (e.g. low socio-economic status [11-13], gastro-oesophageal reflux disease [14], Barrett's oesophagus [15], non-steroidal anti-depressants (NSAIDs)/Aspirin [16]) and also to modifiable lifestyle related factors (e.g. physical inactivity [17], tobacco, alcohol, low intake of fruits and vegetables $[11,18])$.

It is shown that the incidence of oesophageal carcinoma in Sri Lanka has been gradually yet steadily increasing in the recent past. This increase may be due to an increasing trend of adenocarcinoma which shows a more aggressive disease progression $[5,6,19-21]$ than the squamous cell carcinoma which is the commonest histology type (73\% of cases) [5]. Another important reason could be the increased susceptibility owing to increasing trends in the prevalence of risk factors related to lifestyle. It is shown that along with rapid and unplanned urbanization in the last few decades, several unhealthy lifestyle practices have become prominent, such as fruit and vegetable intake being far below the recommended level in 73\% [22]; prevalence of alcohol consumption in urban settings being 30\% [23]; prevalence of current alcohol drinking being $18 \%$, percentage of current smoking being 15\%; and overall prevalence of inactivity being $30 \%$ [22] in Sri Lanka. More importantly, the increasing trends in oesophageal cancer could also be attributable to not yet identified risk factors that are socio-culturally and environmentally unique to countries within a region.

In the recent past, several risk factors have been newly identified related to specific elements in diet (e.g. diet deficient in vitamins A, B, C and E, Selenium and Beta carotene $[24,25]$; food preparation methods (e.g. chillies $[24,26]$ and spicy food [27]); food consumption patterns (e.g. consuming food/drinks at high temperatures [27]); drinking water sources [28]; daily habits (e.g. chewing betel leaf with tobacco [29] and arecanut [30]); and exposure to ionizing radiation [31]. However, almost all these risk factors have been identified in studies carried out among populations in developed countries, and therefore may not directly apply to the risk profile relevant to populations in developing countries. Furthermore, unlike developed countries, most of the developing countries are agriculture based, and thereby exposed to indiscriminate use of agrochemicals and other occupational hazards. Currently, there is minimal research evidence on its risk for oesophageal carcinoma.

Therefore, in order to prioritize primary prevention strategies in low resource settings as in Sri Lanka, it necessitates a detailed assessment of population-specific risk factor profiling. Identification of such specific risk profile for the country would enable the health care planners to prioritize the risk factors that ought to be addressed in primary prevention, and it would be applicable to other developing countries especially in low-resource settings. This study was conducted with the aim of determining the magnitude of risk factors of oesophageal carcinoma among adults in Sri Lanka.

Additional file 1 gives the details of this manuscript being reported based on the STROBE guidelines for reporting observational studies [32].

\section{Methods}

A hospital based unmatched case-control study was conducted among residents in the Western Province during 2015-2016 in Sri Lanka.

\section{Selection of cases}

Cases were newly diagnosed patients of oesophageal carcinoma based on histological confirmation made during last 3 months following upper gastro-intestinal endoscopy (UGIE) examination. The authors recruited the 
cases consecutively from surgical and oncology wards and clinics of the National Cancer Institute, Maharagama (NCIM), which is the premier tertiary referral hospital in Sri Lanka dedicated for treatment and follow up of cancer patients referred from both state (predominantly) and private sector hospitals. It is the only hospital providing in-ward and out-patient care services including chemotherapy and radiotherapy for residents in the Western Province. Critically ill patients, patients with secondary carcinoma (e.g. metastasis) including oesophageal carcinoma, patients diagnosed with any other cancer (confirmed with documental evidence) and patients with relapses of any cancer including oesophageal carcinoma were excluded from the study.

\section{Selection of controls}

Controls were persons excluded of oesophageal carcinoma based on UGIE examination findings. The authors of the study recruited the control group based on the incidence density sampling method (i.e. four controls selected within 1 week of a case recruitment) [33], from the endoscopy unit of the National hospital of Sri Lanka, which is the leading referral unit for patients from state and private sector hospitals for high risk screening (e.g. family screening) and diagnosis of cancer. Patients diagnosed of having any cancer, patients referred for high risk screening for oesophageal carcinoma (e.g. family history), patients with cirrhosis/chronic liver diseases, patients having any oesophageal/gastric structural abnormalities on UGIE such as polyps, ulcers and strictures, patients diagnosed with conditions that may mask visualization of the oesophageal mucosa (e.g. oesophagitis, gastro-oesophageal reflux disease, Barrette's oesophagus, achalasia and/or hiatus hernia) and patients with a history of dyspeptic symptoms persisting for more than six months were excluded from the study. All these exclusions were confirmed by documental evidence and by performing an UGIE examination by two Consultant Gastroenterologists, based on the visualization of apparently healthy oesophageal mucosa, gastro-oesophageal junction and the stomach up to the distal duodenal sphincter with no macroscopic changes, erosions or lesions such as polyps and ulcers.

Controls for the study could not be recruited from the endoscopy unit at NCIM as it provides services mainly for treatment purposes, screening for secondary oesophageal carcinoma and for high risk screening (e.g. family screening), and very rarely for diagnostic purposes of primary oesophageal carcinoma. This selection bias is however assumed to be low as both NCIM and National Hospital of Sri Lanka were comparable by both being tertiary care level state hospitals with similar patient characteristics.

\section{Sample size calculation}

The sample size for case $(n=49)$ and control groups $(n$ =196) for univariate analysis was calculated considering four controls per case, $5 \%$ significance level, beta error of 0.2 and $5 \%$ non-response rate to detect the smallest risk (odds ratio of 2.5 for consumption of alcohol on oesophageal carcinoma [34] and 33\% prevalence of the risk factor among the community controls [35] in Sri Lanka.

\section{Study variables}

Following informed written consent, case and control groups were administered a questionnaire to collect data on socio-demographic characteristics and potential risk factors of oesophageal carcinoma from both case and control groups. These included factors related to personal [e.g. age, sex, ethnicity, level of education, social class (classification based on the occupation [36]) and family history]; occupational and environmental factors (e.g. exposure to agrochemicals, home/industry based chemicals, in-door and out-door air pollution, major source of drinking water); health related factors (e.g. prolonged medication and co-morbidities, exposure to ionizing radiation) and lifestyle related factors (e.g. diet quality and physical activity, alcohol and tobacco use, food/beverages consumed at high temperatures, consumption of coloured beverages and/or spicy food and betel quid chewing).

\section{Validated questionnaires used in the study}

Two already developed and validated questionnaires were used in the current study to assess the quality of the diet and the physical activity of the study participants in both groups. The quality of the diet related to cancer was assessed using a food frequency questionnaire (FFQ), which was developed and validated for assessing the quality of diet in relation to cancer in the district of Colombo [37]. Lifetime total physical activity was assessed using lifetime total physical activity questionnaire which has been validated [37], and used worldwide including in Sri Lanka.

Data related to other study variables were obtained through a pre-tested interviewer administered questionnaire developed by the authors. The judgemental validity of the developed questionnaire was assessed by an expert panel including Oncologists, Onco-surgeons, Consultant Community Physicians, and Psychiatrists. Operational definitions used for each variable in the study are given in Table 1 .

\section{Data analysis}

Data were analysed using the statistical package for the social sciences (SPSS) version 20. Descriptive statistics with mean (SD) for continuous data and proportions for categorical data were used respectively. The risk of each factor in the development of oesophageal carcinoma was assessed using odds ratio (OR) with 95\% confidence 
Table 1 Operational definitions used in the study

\begin{tabular}{ll}
\hline Term & Definition used in the study \\
\hline 'High risk' drinker & A person who has consumed more than three standard drinks on any day or \\
& more than seven standard drinks per week for women, and more than four \\
& drinks on any day or more than 14 per week for men [62]. \\
& Standard drink: Quantity of any type of drink, containing 10 grams of pure \\
& alcohol [62, 63]. \\
& The volume of alcoholic beverage consumed per session was based on standard \\
volume measures for different types of alcoholic beverages consumed (e.g. glass, shots, bottles) & and the total volume of ethanol consumed per session per week was calculated using the \\
standard ethanol amount in the drinks [64].
\end{tabular}

'Sub-optimal' consumption of fibre and antioxidants

'Sub optimal' consumption of deep fried food

Consumption of beverages at extreme temperatures

Consumption of excessive chilli

Food/beverages with excessive colour

'Low' and 'high' total lifetime physical activity levels

Ever smoker

Exposure to passive smoking

Ever betel chewer

Exposure to agrochemicals

Exposure to home/industry based chemicals

Major source of drinking water

Exposure to indoor air pollution

Exposure to outdoor air pollution

Prolonged medication for co-morbid conditions

Vitamin supplementation

Exposure to ionizing radiation
Inadequate consumption of food containing dietary fibre and anti-oxidants [37].

Overconsumption of deep fried food [37].

Daily consumption of hot beverages (tea/coffee) within at least 2 minutes of preparation

Daily consumption of meals prepared with excessive additional chilli

Any coloured food/beverage that would stain the fingers, lips and tongue upon its consumption

Lifetime total physical activity (average MET-hours per week per year) in relation to occupation, household and sports and exercise activities [37, 65]. 'Low' level of physical activity = the score that corresponded with the $25^{\text {th }}$ percentile and 'high' level of the physical activity = the score that corresponded with the $75^{\text {th }}$ percentile of the distribution of total scores of all participants

A person who had smoked 100 or more cigarettes/sticks of bidi in his/her lifetime [66].

A person who has/had been exposed to second hand smoking in confined areas (at home or work) for at least once a week for three consecutive months during the past one year

A person who has/had the habit of betel quid chewing (with or without additives) at least three times per week, continuously for six months or more in the lifetime

Direct and/or indirect exposure to agrochemicals

Where;

'Direct exposure' to agrochemicals = Persons who have been farmers/cultivators for at least six months during which they have been involved in spraying/handling agrochemicals And

'Indirect exposure' to agrochemicals = Persons who have been living at least for six months in close proximity (within $100 \mathrm{~m}$ ) and/or working in close proximity $(10 \mathrm{~m})$ to an environment consistently exposed to agrochemicals

Direct and/or indirect exposure to home/industry based chemicals Where;

Direct exposure $=$ persons who have been working at least six months during

which they were directly exposed to home/industry based chemicals for at least three days per week And

Indirect exposure $=$ Workers who have not been directly handling chemicals, but have been working for at least six months in close proximity (10m radius) to an environment consistently using home/industry based chemicals

The source of drinking water from which he/she consumed water consistently at least once a day, during the last one year.

If there were more than one source (eg: pipe borne water consumption at the work place and consumption of well water at home), most frequently used source of drinking water was considered

Use of fire wood as the main source of fuel in the household and having the kitchen built attached to the house

Person who has been living at least for six months in a place adjacent (within 20m) to a main road and/or living at least for six months in close proximity (within 100m radius) to a factory with smoke emission

A person who had been on a drug regime (oral medications) for at least six consecutive months, during the last 10 years

A person who had been on vitamin supplementation for at least one month consecutively during the last 10 years

A person who has been exposed to any type of ionizing radiation (eg: $\mathrm{X}$-ray, CT, Gamma rays) within the past 10 years irrespective of the indication 
interval. These ORs were adjusted for confounders by carrying out logistic regression (LR) analysis using backward LR method, based on two assumptions: the sample size was adequate for logistic regression analysis (at least 10 cases per independent variable tested) and there was no multicollinearity between the predictor variables [38]. The dependent variable in the LR model was presence or absence of oesophageal carcinoma. Variables that showed a significant association with oesophageal carcinoma at a significance level of 0.05 were included as independent variables into the model. As pre-decided by an expert panel, having less than 10 in the control or case groups [38], variables that were strongly correlated with other variables, variables showing a large confidence interval in the univariate analysis with an upper limit of more than 30 , and variables that were not meaningful and plausibly explained by the model as risk factors were excluded from the LR. Goodness of fit of the LR model was assessed by the overall percentage of prediction of oesophageal carcinoma by the model, chi-square test, Hosmer and Lameshow test, Omnibus test, Cox and Snell Square test and Negelkerke $R^{2}$ tests.

In addition, variables showing significant associations with oesophageal carcinoma were further tested for possible effect modification of the risk for oesophageal carcinoma, and if present, such interactions were also included in the LR analysis.

\section{Results}

The sample consisted of 49 cases and 196 controls. The response rate was $100 \%$. The mean age of cases was 59.8 $(\mathrm{SD}=11.2)$ years ranging between 37 and 79 years, while the mean age of controls was $53.0(\mathrm{SD}=15)$ ranging between 18 and 87 years. The standardized skewness for age in the study was 2.47 and the standardized kurtosis was 1.31. Other basic characteristics of the cases and controls are given in Table 2.

At the time of diagnosis, $85.7 \%$ of cases and $63.3 \%$ of controls were unemployed, and $36.7 \%$ of cases and $43.9 \%$ of the controls belonged to social class V (unskilled labourers, unemployed individuals). Majority of the cases had squamous cell carcinoma (65.3\%); located in the lower thoracic oesophagus (61.2\%); in stage IV $(45 \%)$ and stage III (37\%) of the disease; with moderately differentiated cells $(65.3 \%)$. All cases $(100 \%)$ had sought medical attention following progressive dysphagia, with a mean duration of 2.9 months $(\mathrm{SD}=1.4)$ since the development of first symptom to the diagnosis, with a range of 1-6 months. Also, at the time of diagnosis, most cases $(55.1 \%)$ had been suffering from regurgitation for a mean duration of 1.2 years $(\mathrm{SD}=1.4) ; 49 \%$ from nausea for a mean duration of 0.78 years $(S D=1.1) ; 47 \%$ from heart burn for a mean duration of 0.85 years $(\mathrm{SD}=$ 1.2); $43 \%$ from loss of appetite for a mean duration of
0.7 years $(\mathrm{SD}=1.1)$; and $37 \%$ from vomiting for a mean duration of 0.54 years $(\mathrm{SD}=0.8)$, which they had not attributed to oesophageal carcinoma.

The majority of controls however, were having dyspeptic symptoms (98\%) including complaints of dysphagia (2\%), for which they sought medical attention. On the other hand, controls with a history suggestive of long standing (more than 6 months) dyspeptic symptoms were excluded in the current study and oesophageal carcinoma was excluded following UGIE among them.

Of the several variables that showed significant OR for oesophageal carcinoma in the univariate analysis (Tables 3, 4 and 5), 19 were selected for the LR analysis. Based on these results, the country-specific risk profile for oesophageal carcinoma included: age more than 65 years; family history of cancer; sub-optimal consumption of fibre; sub-optimal consumption of antioxidants; over-consumption of deep fried food; 'low' total lifetime sports and exercise activities; 'high risk' alcohol consumption; ever betel quid chewing; exposure to agrochemicals; consuming pipe-borne water as the major source of water and ever exposure to radiation. The final LR model was able to classify the cases from controls with $90.6 \%$ accuracy compared to $80 \%$ without any of the independent variables used in the model. According to Cox and Snell R square and Nagelkerke R square test results, the model described $45.3-71.7 \%$ of the variability of the dependent variable by the independent variables. Results of Hosmer and Lemeshow test [38] were; $\mathrm{X}^{2}=$ 4.63; $\mathrm{df}=8 ; p=0.796$. Sensitivity of the model was $67.3 \%$, while the specificity was $96.4 \%$. The positive and negative predictive values of the model were $82.5 \%$ and $92.2 \%$ respectively.

Two significant effect modifications between betel quid chewing and male sex $(p=0.01)$, and between ever exposure to radiation and age over 65 years $(p=0.04)$ were also observed. Accordingly, a male with ever betel quid chewing showed a 24-fold risk $(\mathrm{OR}=23.9)$ for oesophageal carcinoma than a male who did not. For a female, this risk was four-fold $(\mathrm{OR}=3.9)$. Also, an individual of over 65 years with ever exposure to radiation had a 24-fold risk $(\mathrm{OR}=23.6)$ for oesophageal carcinoma compared to an individual with no such exposure. For an individual less than 65 years old, this risk was only four-fold $(\mathrm{OR}=3.8)$. However, when the model was re-tested with these effect modifications, those lost their significance.

\section{Discussion}

This study aimed at assessing the population-specific risk factor profile for oesophageal cancer in Sri Lanka in order to supplement the implementation of more targeted preventive programmes for those at risk in order to combat the disease. Our study highlights that the country specific 
Table 2 Distribution of the demographic characteristics of cases and controls

\begin{tabular}{|c|c|c|c|c|}
\hline \multirow[t]{2}{*}{ Demographic characteristic } & \multicolumn{2}{|c|}{ Cases $(N=49)$} & \multicolumn{2}{|c|}{ Controls $(N=196)$} \\
\hline & No. & $\%$ & No. & $\%$ \\
\hline \multicolumn{5}{|l|}{ Sex } \\
\hline Male & 34 & 69.4 & 70 & 35.7 \\
\hline Female & 15 & 30.6 & 126 & 64.3 \\
\hline \multicolumn{5}{|l|}{ Current marital status } \\
\hline Married & 41 & 83.6 & 136 & 69.4 \\
\hline Single & 4 & 8.2 & 39 & 19.8 \\
\hline Divorced/separated/widowed & 4 & 8.2 & 21 & 10.8 \\
\hline \multicolumn{5}{|l|}{ Ethnicity } \\
\hline Sinhala & 43 & 87.8 & 145 & 74.0 \\
\hline Other ethnicities (Tamil, Muslim, Burgher) & 6 & 12.2 & 51 & 26.0 \\
\hline \multicolumn{5}{|l|}{ Highest educational level } \\
\hline Primary and lower & 15 & 30.6 & 31 & 15.8 \\
\hline Secondary & 33 & 67.4 & 153 & 78.0 \\
\hline Tertiary & 1 & 2.0 & 12 & 6.2 \\
\hline \multicolumn{5}{|l|}{ Employment status } \\
\hline Currently employed & 7 & 14.2 & 72 & 36.7 \\
\hline Previously employed & 35 & 71.4 & 59 & 30.1 \\
\hline Never employed & 7 & 14.3 & 65 & 33.2 \\
\hline \multicolumn{5}{|l|}{ Social status ${ }^{\mathrm{a}}$} \\
\hline Social class I-Leading professionals & 1 & 2.0 & 8 & 4.1 \\
\hline Social class II-Lesser professionals & 2 & 4.1 & 18 & 9.2 \\
\hline Social class III-Skilled workers \& non-manual workers & 15 & 30.6 & 56 & 28.6 \\
\hline Social class IV- Partly skilled workers & 13 & 26.5 & 28 & 14.3 \\
\hline Social class V- Unskilled workers ${ }^{b}$ & 18 & 36.7 & 86 & 43.9 \\
\hline \multicolumn{5}{|l|}{ Monthly family income (SLR) } \\
\hline$\leq 20,000$ & 24 & 49 & 88 & 44.9 \\
\hline $20,001-50,000$ & 20 & 40.8 & 90 & 45.9 \\
\hline $50,001-100,000$ & 5 & 10.2 & 15 & 7.7 \\
\hline$>100,000$ & 0 & 0.0 & 3 & 1.5 \\
\hline
\end{tabular}

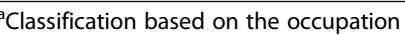

${ }^{\mathrm{b}}$ Based on the classification, the unemployed are included in the social class $\mathrm{V}$ as well

risk factor profile for oesophageal cancer consists of novel risk factors related to lifestyle (sub-optimal consumption of fibre, antioxidants and deep fried food, low total lifetime sports and exercise activities, ever betel quid chewing); environment and occupation (exposure to agrochemicals, pipe-borne drinking water); and health (ever exposure to radiation), in addition to the conventional (age $>65$ years, family history of cancer, high risk alcohol consumption) risk factors. The high risk for oesophageal carcinoma usually associated with conventional risk factors such as male sex and tobacco smoking were not apparent in this study.

Considering the country specific risk factor profile that was identified in the current study, it is important to note that many of these risk factors are shared with other cancers as well. For example, increased age, family history of cancer, low fruits and vegetable consumption resulting in low consumption of fibre and anti-oxidants, over consumption of deep fried food, alcohol consumption, betel quid chewing, physical inactivity and tobacco smoking are shared as risk factors with oral cancer, lung cancer, cervical cancer and breast cancer; some of the most common cancers among Sri Lankan males and females [39]. The National Cancer Control Programme of Sri Lanka should therefore build on the initiatives already taken to improve the risk related to other cancers, such as public awareness programs and empowerment through community based health promotion. In addition, there are regulations related to prohibition of smoking in public places; tobacco 
Table 3 Risk of oesophageal carcinoma associated with demographic, family history and socio-economic characteristics

\begin{tabular}{|c|c|c|c|c|c|c|}
\hline \multirow[t]{2}{*}{ Characteristic } & \multicolumn{2}{|c|}{ Cases $(N=49)$} & \multicolumn{2}{|c|}{ Controls $(N=196)$} & \multirow{2}{*}{$\begin{array}{l}\text { Non-adjusted OR } \\
(95 \% \mathrm{Cl})\end{array}$} & \multirow{2}{*}{$\begin{array}{l}\text { Adjusted OR } \\
(95 \% \mathrm{Cl})\end{array}$} \\
\hline & No. & $\%$ & No. & $\%$ & & \\
\hline \multicolumn{7}{|l|}{ Age } \\
\hline$>65$ years & 17 & 34.7 & 41 & 20.9 & $2.0(1.2-4.0)$ & $4.0(1.2-14.2)$ \\
\hline$\leq 65$ years $\left(\right.$ reference) ${ }^{a}$ & 32 & 65.3 & 155 & 79.1 & 1.0 & 1.0 \\
\hline \multicolumn{7}{|l|}{ Sex } \\
\hline Male & 34 & 69.4 & 70 & 35.7 & $4.1(2.1-8.0)$ & $N S^{b}$ \\
\hline Female (reference) ${ }^{a}$ & 15 & 30.6 & 126 & 64.3 & 1.0 & \\
\hline \multicolumn{7}{|l|}{ Family history of cancer } \\
\hline Yes & 11 & 22.4 & 20 & 10.2 & $2.6(1.1-5.8)$ & $5.0(1.3-19.0)$ \\
\hline No $(\text { reference) })^{a}$ & 38 & 77.6 & 176 & 89.8 & 1.0 & 1.0 \\
\hline \multicolumn{7}{|l|}{ Employment status } \\
\hline Ever employed $^{d}$ & 42 & 85.7 & 132 & 67.4 & $2.9(1.2-6.8)$ & $N S^{b}$ \\
\hline Never employed (reference) ${ }^{a}$ & 7 & 14.3 & 64 & 32.6 & 1.0 & \\
\hline \multicolumn{7}{|l|}{ Social status } \\
\hline Low (social class III, IV \& V) & 46 & 93.9 & 170 & 86.7 & $2.35(0.7-8.1)$ & - \\
\hline High (social class I \& II) (reference) ${ }^{a}$ & 3 & 6.1 & 26 & 13.3 & 1.0 & \\
\hline \multicolumn{7}{|l|}{ Monthly family income (SLR) } \\
\hline$\leq 20,000$ & 24 & 49.0 & 88 & 44.9 & $1.2(0.6-2.2)$ & - \\
\hline$>20,000{\text { (reference) })^{a}}^{a}$ & 25 & 51.0 & 108 & 55.1 & 1.0 & \\
\hline
\end{tabular}

${ }^{\text {a }}$ The category having the lesser proportion of cases

${ }^{b}$ Not significant in the logistic regression model

'Previously employed \& currently employed categories were amalgamated for univariate analysis

advertising, promotion and sponsorship; having $80 \%$ pictorial warnings on tobacco package [40] implemented in Sri Lanka. Also, manufacturing, importing, selling or offer to sale of any smokeless tobacco products or mixture of any flavoured, coloured or sweetened cigarettes or electronic cigarettes that contain tobacco is prohibited in Sri Lanka. Increased taxation of tobacco and alcohol, prohibition of selling tobacco to children less than 21 years and alcohol to less than 18 years are a few other legislations undertaken to limit the affordability, availability and delay the age of initiation [40]. These should be strictly enforced in the country.

Optimal consumption of dietary fibre and antioxidants is known to lower the risk of oesophageal carcinoma [41, 42]. This relationship is reinforced in the current study, while highlighting several implications in countries having tropical climates such as in South East Asia, West Africa, Central Africa and the Caribbean, which are rich in tropical fruits, vegetables, pulses and legumes. Most of these foods are home grown in the dry zone in Sri Lanka. Therefore, options should be explored collectively by the agricultural sector and the health planners in encouraging a diet rich in fruits and vegetables as a preventive strategy for oesophageal carcinoma.

In developing countries, urbanization, industrialization and economic transition has resulted in a shift of the usual dietary patterns of the people from fruits and vegetable based diet to increased consumption of processed food; from home-cooked food to take-away fast foods; and increased use of fats and sugar sweetened beverages [43]. In Sri Lanka, unhealthy dietary behaviour related to high consumption of deep fried food and added sugar is well established in urban areas [44] and fast spreading to the rural areas. In this background, the consumption of energy dense, deep fried food will further increase the risk of oesophageal cancer [45] and therefore, specific preventive strategies such as effective implementation of the healthy canteen policy in schools [46] and at work places; nutrient profiling; traffic light front of pack food labelling and limiting advertising of such energy dense and sugar sweetened food/beverages to children during the prime television viewing times should be undertaken in the country to combat these risk factors.

There are many studies that show a positive relationship between obesity and oesophageal carcinoma, predominantly for adenocarcinoma [47, 48]. Lagergren et al. (1999) showed that the risk of obese persons [Body Mass Index $(\mathrm{BMI})>30 \mathrm{~kg} / \mathrm{m}^{2}$ ] for oesophageal carcinoma compared to those with BMI $<22 \mathrm{~kg} / \mathrm{m}^{2}$ was 16 -fold $(\mathrm{OR}=16.2$; 95\% CI: 6.3, 41.4) [47]. However, in the present study, overweight and obesity (BMI $\geq 25 \mathrm{~kg} / \mathrm{m}^{2}$ ) showed potentially an inverse relationship with the risk 
Table 4 Risk of oesophageal carcinoma associated with the modifiable life style related factors

\begin{tabular}{|c|c|c|c|c|c|c|}
\hline \multirow[t]{2}{*}{ Characteristic } & \multicolumn{2}{|c|}{ Cases $(N=49)$} & \multicolumn{2}{|c|}{ Controls $(N=196)$} & \multirow{2}{*}{$\begin{array}{l}\text { Non-adjusted } \\
\text { OR (95\% Cl) }\end{array}$} & \multirow{2}{*}{$\begin{array}{l}\text { Adjusted OR } \\
(95 \% \mathrm{Cl})\end{array}$} \\
\hline & No. & $\%$ & No. & $\%$ & & \\
\hline \multicolumn{7}{|l|}{ Dietary fibre } \\
\hline Sub-optimal & 22 & 44.9 & 15 & 7.7 & $9.83(4.6-21.2)$ & $3.58(1.1-12.3)$ \\
\hline Optimal (reference) ${ }^{a}$ & 27 & 55.1 & 181 & 92.3 & 1.0 & 1.0 \\
\hline \multicolumn{7}{|l|}{ Anti-oxidants } \\
\hline Sub-optimal & 32 & 65.3 & 44 & 22.4 & $6.5(3.3-12.8)$ & $7.0(2.2-22.5)$ \\
\hline Optimal (reference) ${ }^{a}$ & 17 & 34.7 & 152 & 77.6 & 1.0 & 1.0 \\
\hline \multicolumn{7}{|l|}{ Deep fried food } \\
\hline Sub-optimal $^{\mathrm{b}}$ & 26 & 53.1 & 44 & 22.4 & $3.91(2.0-7.5)$ & $6.68(2.0-22.6)$ \\
\hline Optimal (reference) ${ }^{a}$ & 23 & 46.9 & 152 & 77.6 & 1.0 & 1.0 \\
\hline \multicolumn{7}{|c|}{ Beverages (tea/coffee) at extremely hot temperatures } \\
\hline Yes & 21 & 42.9 & 9 & 4.6 & $15.6(6.5-37.4)$ & Excluded from $L R^{c}$ \\
\hline No (reference) $^{a}$ & 28 & 57.1 & 187 & 95.4 & 1.0 & \\
\hline \multicolumn{7}{|c|}{ Meals containing excessive amount of chillies } \\
\hline Yes & 36 & 73.5 & 15 & 7.7 & $33.4(14.7-76.2)$ & Excluded from $L R^{c}$ \\
\hline No (reference) $^{\mathrm{a}}$ & 13 & 26.5 & 181 & 92.3 & 1.0 & \\
\hline \multicolumn{7}{|l|}{ Food/drink with excessive colouring } \\
\hline Yes & 40 & 81.6 & 34 & 17.3 & $21.2(9.4-47.7)$ & Excluded from $L R^{c}$ \\
\hline No (reference) $^{a}$ & 9 & 18.4 & 162 & 82.7 & 1.0 & \\
\hline \multicolumn{7}{|l|}{ Alcohol consumption } \\
\hline Yes & 30 & 61.2 & 45 & 23.0 & $5.3(2.7-10.3)$ & Excluded from $L R^{c}$ \\
\hline No (reference) $^{a}$ & 19 & 38.8 & 151 & 77.0 & 1.0 & \\
\hline \multicolumn{7}{|l|}{ Risk drinking category } \\
\hline High risk drinking & 27 & 55.1 & 18 & 9.2 & $12.14(5.8-25.5)$ & $11.7(2.8-49.4)$ \\
\hline Low risk drinking ${ }^{d}$ & 3 & 6.1 & 27 & 13.8 & & \\
\hline never consumers ${ }^{d}$ (reference) ${ }^{a}$ & 19 & 38.8 & 151 & 77.0 & 1.0 & 1.0 \\
\hline \multicolumn{7}{|l|}{ Smoking status } \\
\hline Ever smoker & 28 & 57.1 & 21 & 10.7 & $11.1(5.4-22.9)$ & $N S^{e}$ \\
\hline Never smoker (reference) ${ }^{a}$ & 21 & 42.9 & 175 & 89.3 & 1.0 & \\
\hline \multicolumn{7}{|l|}{ Exposure to passive smoking } \\
\hline Yes & 32 & 65.3 & 24 & 12.2 & $13.49(6.5-27.9)$ & $N S^{e}$ \\
\hline No (reference) $^{a}$ & 17 & 34.7 & 172 & 87.8 & 1.0 & \\
\hline \multicolumn{7}{|l|}{ Betel quid chewing } \\
\hline Ever chewed & 31 & 63.3 & 21 & 10.7 & $14.35(6.8-30.0)$ & $6.1(2.0-20.0)$ \\
\hline Never chewed (reference) ${ }^{a}$ & 18 & 36.7 & 175 & 89.3 & 1.0 & 1.0 \\
\hline \multicolumn{7}{|c|}{ Lifetime total occupational activities (MET hours/week/year) f $^{f}$} \\
\hline Low $(<1.0)$ & 10 & 20.4 & 66 & 33.7 & $0.51(0.2-1.1)$ & $N S^{e}$ \\
\hline Average $(1.0-218.1)^{9}$ & 17 & 34.7 & 91 & 46.4 & & \\
\hline High $(>218.1)^{\mathrm{a}}$ (reference) $^{\mathrm{g}}$ & 22 & 44.9 & 39 & 19.9 & 1.0 & \\
\hline \multicolumn{7}{|c|}{ Lifetime total household activities (MET hours/week/year) ${ }^{f}$} \\
\hline Low $(<40.7)$ & 26 & 53.1 & 35 & 17.9 & $5.2(2.7-10.2)$ & $N S^{e}$ \\
\hline Average $(40.7-323.8)^{h}$ & 21 & 42.9 & 104 & 53.1 & & \\
\hline High $(>323.8)^{\mathrm{h}}$ (reference) $^{\mathrm{a}}$ & 2 & 4.1 & 57 & 29.1 & 1.0 & \\
\hline
\end{tabular}

Lifetime total sports and exercise activities (MET hours/week/year) ${ }^{f}$ 
Table 4 Risk of oesophageal carcinoma associated with the modifiable life style related factors (Continued)

\begin{tabular}{|c|c|c|c|c|c|c|}
\hline \multirow[t]{2}{*}{ Characteristic } & \multicolumn{2}{|c|}{ Cases $(N=49)$} & \multicolumn{2}{|c|}{ Controls $(N=196)$} & \multirow{2}{*}{$\begin{array}{l}\text { Non-adjusted } \\
\text { OR (95\% CI) }\end{array}$} & \multirow{2}{*}{$\begin{array}{l}\text { Adjusted OR } \\
(95 \% \mathrm{Cl})\end{array}$} \\
\hline & No. & $\%$ & No. & $\%$ & & \\
\hline Low $(<1.0)$ & 39 & 79.6 & 111 & 56.6 & $2.99(1.4-6.3)$ & $5.83(1.5-23.0)$ \\
\hline Average $(1.0-40.0)^{i}$ & 5 & 10.2 & 30 & 15.3 & & \\
\hline High $(>40.0)^{i}$ (reference) $^{a}$ & 5 & 10.2 & 55 & 28.1 & 1.0 & 1.0 \\
\hline
\end{tabular}

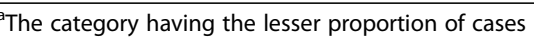

${ }^{b}$ Sub-optimal consumption of deep fried food indicates over consumption levels

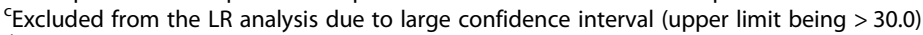

${ }^{d}$ Low risk drinking and never consumer categories were amalgamated for univariate analysis

${ }^{\mathrm{e}}$ Not significant in the logistic regression model

${ }^{\mathrm{f}}$ The highest and the lowest quartiles of the activity were considered as the cut off points

$g, h, i$ Average and high levels of physical activity categories were amalgamated for univariate analysis

Table 5 Risk of oesophageal carcinoma associated with occupational, environmental and health related factors

\begin{tabular}{|c|c|c|c|c|c|c|}
\hline \multirow[t]{2}{*}{ Characteristic } & \multicolumn{2}{|c|}{ Cases } & \multicolumn{2}{|c|}{ Controls } & \multirow{2}{*}{$\begin{array}{l}\text { Non-adjusted } \\
\text { OR (95\% Cl) }\end{array}$} & \multirow{2}{*}{$\begin{array}{l}\text { Adjusted OR } \\
(95 \% \mathrm{CI})\end{array}$} \\
\hline & No. & $\%$ & No. & $\%$ & & \\
\hline \multicolumn{7}{|l|}{ Exposure to agrochemicals } \\
\hline Ever exposed & 19 & 38.8 & 19 & 9.7 & $5.9(2.8-12.4)$ & $6.57(1.4-30.3)$ \\
\hline Never exposed (reference) ${ }^{a}$ & 30 & 61.2 & 177 & 90.3 & 1.0 & 1.0 \\
\hline \multicolumn{7}{|c|}{ Exposure to other home/industry based chemicals } \\
\hline Ever exposed & 11 & 22.4 & 9 & 4.6 & $6.0(2.3-15.5)$ & $N S^{b}$ \\
\hline Never exposed (reference) ${ }^{a}$ & 38 & 77.6 & 187 & 95.4 & 1.0 & \\
\hline \multicolumn{7}{|l|}{ Major source of drinking water } \\
\hline Pipe borne water & 27 & 55.1 & 65 & 33.2 & $2.47(1.3-4.7)$ & $5.62(1.7-18.9)$ \\
\hline 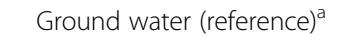 & 22 & 44.9 & 131 & 66.8 & 1.0 & 1.0 \\
\hline \multicolumn{7}{|l|}{ Indoor air pollution } \\
\hline Yes & 39 & 79.6 & 18 & 9.2 & $38.6(16.5-90.0)$ & $N S^{b}$ \\
\hline No (reference) ${ }^{\mathrm{a}}$ & 10 & 20.4 & 178 & 90.8 & 1.0 & \\
\hline \multicolumn{7}{|l|}{ Outdoor air pollution } \\
\hline \multicolumn{7}{|l|}{ a. Factory in close vicinity } \\
\hline Yes & 4 & 8.2 & 16 & 8.2 & $1.0(0.32-3.1)$ & - \\
\hline No (reference) ${ }^{a}$ & 45 & 91.8 & 180 & 91.8 & 1.0 & \\
\hline \multicolumn{7}{|c|}{ b. House situated adjacent to a main road } \\
\hline Yes & 20 & 40.8 & 53 & 27.0 & $1.86(1.0-3.6)$ & - \\
\hline No & 29 & 59.2 & 143 & 73.0 & 1.0 & \\
\hline \multicolumn{7}{|l|}{ On prolonged medication } \\
\hline Yes & 4 & 8.2 & 13 & 6.6 & $1.25(0.4-4.0)$ & - \\
\hline No $\left(\right.$ reference) ${ }^{\mathrm{a}}$ & 45 & 91.8 & 183 & 93.4 & 1.0 & \\
\hline \multicolumn{7}{|l|}{ On vitamin supplementation } \\
\hline Yes & 1 & 2.0 & 3 & 1.5 & $1.34(0.1-13.2)$ & - \\
\hline No $(\text { reference) })^{a}$ & 48 & 98.0 & 193 & 98.5 & 1.0 & \\
\hline \multicolumn{7}{|l|}{ Exposure to radiation } \\
\hline Ever exposed & 19 & 38.8 & 19 & 9.7 & $5.9(2.8-12.4)$ & $4.64(1.4-15.5)$ \\
\hline Never exposed (reference) ${ }^{a}$ & 30 & 61.2 & 177 & 90.3 & 1.0 & 1.0 \\
\hline
\end{tabular}

${ }^{a}$ The category having the lesser proportion of cases

${ }^{\mathrm{b}}$ Not significant in the logistic regression model 
of oesophageal carcinoma (unadjusted $\mathrm{OR}=0.07,95 \%$ CI: 0.02-0.2). Oesophageal carcinoma is a common disease to lose weight due to its disease process. The anthropometry measurements in the current study were taken at the time of recruitment, after the onset of the disease, by which time a higher proportion of cases had lost their weight. Therefore, the findings of the current study did not portray the correct picture of the actual status. Therefore, the authors did not include the findings of BMI in the manuscript. The best method to assess the relationship between the overweight/obesity and oesophageal carcinoma would be to assess the overweight/obesity level prior to the onset of the disease, which is not feasible in a case-control study.

The Asian diet especially in South Asia is usually spicy and excessively coloured compared to other countries in the world. In the current study, frequent consumption of meals with excessive chillies was a potential risk factor in the univariate analysis. In concurrence, a study conducted in Assam, India showed similar results [26], while it was in contrast to the findings from Australia [49]. Also, consumption of food/beverages with excessive colouring was found to be a potential risk factor in the current study. This denotes the possibility of these factors being region specific risk factors for oesophageal carcinoma resulting in its high incidence rate. Therefore, the association of these factors with oesophageal carcinoma need to be further explored.

The association of high-risk alcohol consumption with oesophageal cancer demonstrated in the current study was in concurrence with other studies done in Western countries and China [18, 34]. Many studies globally have also shown that smoking is a risk factor for oesophageal carcinoma $[25,50]$. However, though tobacco smoking was identified as a potential risk factor in the univariate analysis, the current study failed to show such a relationship following the multivariate analysis. High correlation with other risk factors such as alcohol consumption and betel chewing could be a reason for this result. On the other hand, detection of a significant association could have been limited by the small sample size of the current study. Despite strong evidence in the literature showing male sex as a risk factor for oesophageal cancer [1, 51], the current study failed to show such a relationship but possible effect modification by the male sex on the relationship between betel quid chewing and oesophageal carcinoma. This implies that the vulnerability of males for oesophageal cancer is only through their behavioural (e.g. alcohol consumption, betel chewing, poor diet quality), and environment and occupational risk factors (agrochemical exposure). This is an important finding for the planners of preventive programmes in the country, where the lifestyle modification especially among the males should be stressed upon. However, the small sample size of the current study urges the need for larger studies to assess the association of male sex and oesophageal carcinoma.

Noteworthy findings of this study are novel risk factors of oesophageal cancer identified in relation to occupation and environment. However, these findings especially on the exposure to agrochemicals were in contrast to many studies. A population based endoscopic survey conducted in the northern part of the Henan province, China, found that there is no association between the exposure to pesticides and oesophageal squamous cell carcinoma or its precursor lesion (OR $=1.0 ; 95 \%$ CI: 0.7, 1.4) [52]. A study conducted in Nebraska found that there is no association of adenocarcinoma with ever-use of insecticides $(\mathrm{OR}=0.7$; 95\% CI: $0.4,1.1)$ or herbicides (OR $=0.7 ; 95 \%$ CI: $0.4,1.2$ ) [53]. Since all these studies including our study have considered exposure to agrochemicals as a proxy measure, further exploration of this relationship using exact measurements of the pollutants in the environment is highly recommended.

With regards to the risk pertaining to drinking water source, a cohort study conducted in Linxian, China, found that the piped water was inversely associated with oesophageal carcinoma $(\mathrm{OR}=0.86 ; 95 \% \mathrm{CI}: 0.78,0.96)$ [25]. A matched case-control study conducted in Iran also found that drinking un-piped water was a risk for oesophageal squamous cell carcinoma $(\mathrm{OR}=4.25$; 95\% CI: $2.2,8.1)$ and this risk increased with every 10 years of drinking un-piped water with an OR of 1.47 (95\% CI: 1.2, 1.8) [54]. In contrast, pipe-borne water was seen to have a six-fold risk for oesophageal carcinoma in the present study compared to other sources of water. Although pipe-borne water supply is regulated at national level in Sri Lanka, and being treated through physical and chemical methods to improve the quality at the point of source, re-contamination could occur during the distribution to consumers owing to inadequacies of the infrastructure (e.g. leaking conveyances), and unsafe storage and handling practices of the consumer [55]. Also, it could be due to the contamination of water sources with heavy metals. A local study found that the largest source of drinking water in the district of Colombo is contaminated with heavy metals such as Tin, Zinc, Cobalt, Iron and Nickel [56]. Additionally, adjacent dug wells are reported to be contaminated with heavy metals such as Lead, Cadmium and Zinc, most likely due to pollution by industries established around these water sources [56]. Further exploration is therefore highly recommended on the relationship of heavy metal contamination of water with oesophageal carcinoma.

It is shown that oesophageal carcinoma is strongly related with old age [57]. Based on the available cancer incidence data for Sri Lanka, most cases of oesophageal carcinoma were in the 65-69 year age group for males, 
although a rise in its incidence was apparent after 40 years of age for both sexes [5, 39]. Therefore, 65 years was taken as the cut off for assessing age as a risk factor for oesophageal carcinoma in the current study, which demonstrated a significant association with oesophageal carcinoma. Also, the high risk of oesophageal cancer associated with family history of cancer is shown in many studies globally [58, 59] including the current study, highlighting the importance of family screening. These factors emphasise the significance of screening the high risk population for oesophageal carcinoma by UGIE. However, this may not be feasible in a low resource country like Sri Lanka owing to the associated prohibitive cost, unavailability of equipment and trained/skilled personnel. This points out the importance of developing risk prediction models based on the country specific risk factors, so that the individuals with substantial risk can be timely identified and referred for endoscopic examination to exclude oesophageal cancer.

\section{Strengths and limitations}

Although the largest calculated sample size (based on the latest available local and international literature) was considered in the present study, the sample seemed not powered enough to detect a significant association with some of the potential risk factors (e.g. tobacco smoking and male sex) owing to small numbers in one or more of its categories. Therefore, larger studies to detect the association of these factors with oesophageal carcinoma is recommended.

The ideal control group for this study was apparently healthy persons recruited from the community who show no upper gastro-intestinal signs on UGIE. However, this was not possible as UGIE is not a routine screening procedure in hospitals and it is difficult to motivate an apparently healthy person to undergo it owing to the cost and invasiveness of the procedure. On the other hand, the mere absence of symptoms also cannot exclude oesophageal carcinoma, as symptoms develop only with substantial involvement of the tumour [60]. Thus, to avoid this misclassification bias, persons presenting with dyspeptic symptoms to the hospital for UGIE examination, had to be taken as controls. Not being apparently healthy, this control group may differ from the general population, as they may have higher exposure rates for the risk factors of oesophageal carcinoma such as alcohol consumption, consumption of deep fried food and spicy food. This possible sharing of risk factors might have resulted in a reduction in the magnitude of the risk of the risk profile identified for oesophageal carcinoma.

The current study was conducted in the Western province of Sri Lanka which is the most populated and the authors are aware that one may argue with the generalizability of the study findings. However, the Western province consists of the highest socio-economic diversity and include people from urban, rural and estate sectors [61]. Therefore, findings from the Western province related to risk factor profile is assumed not to differ much from the rest of the country. Nevertheless, the magnitude of the risk for a certain risk factor may differ for each province. Also, the sample size for the current study was calculated to capture the smallest risk reported in literature of the potential risk factors. Thus, even though there is a possibility of the risk magnitude to be differ for each province, the risk factor profile more or less could be generalizable to the country.

\section{Conclusions}

The country specific risk factor model for oesophageal carcinoma includes novel and modifiable risk factors in relation to diet, occupation, environment and health related factors, in contrast to lesser risk associated with already known conventional risk factors. This emphasizes the need for developing community based targeted educational programmes and targeted preventive activities to combat the risk factors of oesophageal carcinoma for its primary prevention in Sri Lanka.

\section{Additional file}

Additional file 1: STROBE Statement- for case-control studies. Description of data: STROBE statement checklist for the items to be included in reporting case-control studies. (DOCX $33 \mathrm{~kb})$

\section{Abbreviations}

BMI: Body Mass Index; DALY: Disability Adjusted Life Years; FFQ: Food Frequency Questionnaire; LR: Logistic Regression; NCIM: National Cancer Institute, Maharagama; NSAIDs: Non-Steroidal Anti-Depressants; OR: Odds Ratio; SPSS: Statistical Package for the Social sciences; UGIE: Upper GastroIntestinal Endoscopy; YLD: Years Lived with Disability; YLL: Year of Life Lost

\section{Acknowledgements}

Authors acknowledge the support extended by the staff of NCIM and National Hospital of Sri Lanka and the family members of all study participants.

\section{Funding}

The research was partly funded by the Medical Research Institute, Colombo, Sri Lanka. The funding body did not have any direct role in the design of the study, analysis, interpretation of data and in writing the manuscript.

Availability of data and materials

Data will not be shared as prior permission to share data was not obtained.

\section{Authors' contributions}

IA was the principal investigator of the study. IA, MN and CA have made substantial contributions to the conception, design and interpretation of the data. IA collected and analysed the data. CA and IA drafted the manuscript and critically analysed for its intellectual content. IA, CA and MN agree to be accountable for all aspects of the work in ensuring that questions related to the accuracy or integrity of any part of the work are appropriately investigated and resolved. All authors have read and approved the final manuscript.

\section{Authors' information}

IA is a specialist in Community Medicine, has Masters degree and Doctorate of Medicine in Community Medicine and is attached to the Ministry of 
Health, Nutrition and Indigenous Medicine, Sri Lanka and currently serving at the National programme for prevention and control of non-communicable diseases.

MN is a Consultant Gastroenterologist, has Doctorate of Medicine in Medicine, currently serving at the National Hospital of Sri Lanka. CA is a Professor in Community Medicine and has Masters Degree and Doctorate of Medicine in Community Medicine, attached to the Department of Community Medicine, Faculty of Medicine, University of Colombo, Sri Lanka.

\section{Ethics approval and consent to participate}

Ethics clearance was obtained from the ethics review committee of the Faculty of Medicine, University of Colombo, Sri Lanka. Administrative clearance was obtained from the Directors and the relevant Specialists of the NCIM and the National Hospital of Sri Lanka. Written informed consent was obtained from all the eligible participants of the study.

\section{Consent for publication}

Not applicable.

\section{Competing interests}

The authors declare that they have no financial and non-financial competing interests.

\section{Publisher's Note}

Springer Nature remains neutral with regard to jurisdictional claims in published maps and institutional affiliations.

\section{Author details}

${ }^{1}$ National Programme for prevention and control of non-communicable diseases; Ministry of Health, Nutrition and Indigenous Medicine, Colombo, Sri Lanka. ${ }^{2}$ National Hospital, Colombo, Sri Lanka. ${ }^{3}$ Department of Community Medicine, Faculty of Medicine, University of Colombo, Colombo, Sri Lanka.

\section{Received: 7 September 2018 Accepted: 19 October 2018}

\section{Published online: 19 November 2018}

\section{References}

1. GLOBOCAN. Estimated cancer incidence, mortality and prevalence worldwide in 2012. In: Fact sheets; 2012.

2. Marmot M, Atinmo T, Byers T, Chen J, Hirohata T, Jackson A, James W, Kolonel L, Kumanyika S, Leitzmann C et al: Food, Nutrition,Physical activity and the prevention of Cancer: a global perspective: World Cancer Research Fund/American Institute for Cancer Research; 2007

3. Global burden of disease cancer collaboration. The global burden of cancer 2013. JAMA Oncology. 2015;1(4):505-27.

4. Di Pardo BJ, Bronson NW, Diggs BS, Thomas CR Jr, Hunter JG, Dolan JP. The global burden of esophageal Cancer: a disability-adjusted life-year approach. World J Surg. 2015.

5. National Cancer Control Programme: Cancer incidence data: Sri Lanka: 2009. In: Cancer incidence data. Edited by Programme NCC. Colombo, Sri Lanka: Ministry of Health, Sri Lanka; 2015.

6. National Cancer Control Programme: Cancer Incidence Data: Sri lanka Year 2007. 2013.

7. World Bank: Tackling Non-Communicable Diseases in Sri Lanka. 2011.

8. World Cancer Declaration. https://www.uicc.org/sites/main/files/private/ 131119_UICC_WorldCancerDeclaration_2013_1.pdf.

9. Ministry of Health NIM. National Policy and strategic framework on Cancer prevention and control. Colombo: Programme NCC; 2015.

10. Akbari MR, Malekzadeh $R$, Nasrollahzadeh D, Amanian D, Sun P, Islami F, Sotoudeh M, Semnani S, Boffeta P, Dawsey SM, et al. Familial risks of esophageal cancer among the Turkmen population of the Caspian littoral of Iran. Int J Cancer. 2006;119(5):1047-51.

11. Cook-Mozaffari PJ, Azordegan F, Day NE, Ressicaud A, Sabai C, Aramesh B. Oesophageal cancer studies in the Caspian Littoral of Iran: results of a casecontrol study. Br J Cancer. 1978, 39(3):293-309.

12. Brown LM, Hoover $R$, Silverman D, Baris D, Hayes $R$, Swanson GM, Schoenberg J, Greenberg R, Liff J, Schwartz A, et al. Excess incidence of squamous cell esophageal cancer among US black men: role of social class and other risk factors. Am J Epidemiol. 2001;153(2):114-22.
13. Subasinghe D, Samarasekera D. Delay in the diagnosis of esophageal carcinoma: experience of a single unit from a developing country. Indian J Cancer. 2010;47(2):151-5.

14. Solaymani-Dodaran M, Logan RF, West J, Card T, Coupland C. Risk of oesophageal cancer in Barrett's oesophagus and gastro-oesophageal reflux. Gut. 2004;53(8):1070-4.

15. Shaheen N, Ransohoff DF. Gastroesophageal reflux, Barrett esophagus, and esophageal cancer: scientific review. JAMA. 2002;287(15):1972-81.

16. Corley DA, Kerlikowske K, Verma R, Buffler P. Protective association of aspirin/NSAIDs and esophageal cancer: a systematic review and metaanalysis. Gastroenterology. 2003;124(1):47-56.

17. Singh S, Devanna S, Edakkanambeth Varayil J, Murad MH, Iyer PG. Physical activity is associated with reduced risk of oesophageal cancer, particularly oesophageal adenocarcinoma: a systematic review and meta-analysis. BMC Gastroenterol. 2014;14:101.

18. Prabhu A, Obi KO, Rubenstein $\mathrm{JH}$. The synergistic effects of alcohol and tobacco consumption on the risk of oesophageal squamous cell carcinoma: a meta-analysis. Am J Gastroenterol. 2014;109(6):822-7.

19. National Cancer Control Programme: Cancer incidence data: Sri Lanka: 2005. In: Cancer Incidence Data. Edited by national cancer control programme. Colombo, Sri Lanka: Ministry of Healthcare and Nutrition, Sri Lanka; 2009.

20. National Cancer Control Programme: Cancer Incidence Data: Sri Lanka: 2006. In: Cancer Incidence Data. Edited by National cancer control programme. Colombo, Sri Lanka: Ministry of Healthcare and Nutrition; 2012.

21. National cancer control programme: Cancer Incidence Data: Sri Lanka, 2008. In: Cancer Incidence Data. Edited by programme Ncc. Colombo: National Cancer Control Programme; 2014.

22. Ministry of Health Nutrition and Indigenous Medicine.: Non communicable disease risk factor survey: Sri Lanka. In: Non communicable disease risk factor survey: Sri Lanka. Edited by Unit N. Colombo: Ministry of Health Nutrition and Indigenous Medicine; 2015.

23. Katulanda P, Ranasinghe C, Rathnapala A, Karunaratne N, Sheriff R, Matthews D. Prevalence, patterns and correlates of alcohol consumption and its' association with tobacco smoking among Sri Lankan adults: a crosssectional study. Bio Med Central Public Health. 2014;14:612.

24. Kamangar F, Chow W-H, Abnet C, Dawsey S. Environmental causes of esophageal Cancer. Gastroenterol Clin N Am. 2009;38(1):27-57.

25. Tran GD, Sun XD, Abnet CC, Fan JH, Dawsey SM, Dong ZW, Mark SD, Qiao YL, Taylor PR. Prospective study of risk factors for esophageal and gastric cancers in the Linxian general population trial cohort in China. Int J Cancer. 2005;113(3): 456-63.

26. Phukan RK, Chetia CK, Ali MS, Mahanta J. Role of dietary habits in the development of esophageal cancer in Assam, the north-eastern region of India. Nutr Cancer. 2001;39(2):204-9.

27. Islami F, Boffetta P, Ren J-S, Pedoeim L, Khatib D, Kamangar F. Hightemperature beverages and foods and esophageal Cancer risk -- a systematic review. Int J Cancer. 2009;125(3):491-524.

28. Xibib S, Meilan H, Moller H, Evans HS, Dixin D, Wenjie D, Jianbang L. Risk factors for oesophageal cancer in Linzhou, China: a case control study. Asian Pac J Cancer Prev. 2003;4(2):119-24.

29. Nayar D, Kapil U, Joshi YK, Sundaram KR, Srivastava SP, Shukla NK, Tandon RK. Nutritional risk factors in esophageal cancer. J Assoc Physicians India. 2000:48(8):781-7.

30. Akhtar S. Areca nut chewing and esophageal squamous-cell carcinoma risk in Asians: a meta-analysis of case-control studies. Cancer Causes Control. 2013;24(2):257-65

31. Wang J-X, Inskip PD, Boic JD Jr, Li BX, Zhang JY, Fraumeni JF Jr. Cancer incidence among medical diagnostic X-ray workers in China, 1950 to 1985. Int J Cancer. 1990:45(5):889-95.

32. STROBE statement: strengthening the reporting of observational studies in epidemiology. https://www.strobe-statement.org/index.php?id=strobe-home.

33. Miettinen O. Estimability and estimation in case-referent studies. Am J Epidemiol. 1976;103(2):226-35.

34. Yang CX, Wang HY, Wang ZM, Du HZ, Tao DM, Mu XY, Cheng HG, Lei $Y$, Matsuo K, Tajima K. Risk factors for oesophageal cancer: a case control study in South- Western China. Journal of Cancer Prevention. 2005;6(1):48-53

35. De Silva V, Samarasinghe D, Gunawardena N. Alcohol and tobacco use among males in two districts in Sri Lanka. Ceylon Med J. 2009;54(4): $119-24$

36. Barker DJP, Hall AJ. Practical Epidemiology. Edinburgh: Churchill Livingstone; 1991. 
37. Kumari PBVR: Risk factors and risk assessment of breast cancer among women in the district of Colombo. Post graduate Institute of Medicine, University of Colombo; 2013.

38. Pallant J. SPSS survival manual - a step by step guide to data analysis using SPSS for windows (version 12). 2nd ed. Sydney: Allen \& Unwin; 2005.

39. National Cancer control Programme. Cancer Incidence Data: Sri Lanka, 2010. In: Cancer Incidence Data. Edited by Programme NCC. Colombo: National Cancer Control Programme, Sri Lanka; 2016.

40. National authority on tobacco and alcohol act. NATA act. In: Edited by alcohol Naota. Colombo: Government publications bureau, Democratic socialist republic of Sri Lanka; 2006.

41. Sun L, Zhang Z, Xu J, Xu G, Liu X: Dietary Fiber intake reduces risk for Barrett's esophagus and esophageal Cancer. Crit Rev Food Sci Nutr. 2015. EPub ahead of print.

42. Navarro Silvera SA, Mayne ST, Risch H, Gammon MD, Vaughan T, Chow WH, Dubrow R, Schoenberg J, Stanford JL, West AB, et al. Food group intake and risk of subtypes of esophageal and gastric cancer. Int J Cancer. 2008; 123(4):852-60.

43. Popkin BM, Adair LS, Shu wen n. NOW AND THEN: the global nutrition transition: the pandemic of obesity in developing countries. Nutrition Reviewes. 2012;70(1):3-21.

44. Jayawardena R, Nuala MB, Soares MJ, Katulanda P, Hills AP. Food consumption of Sri Lankan adults: an appraisal of serving characteristics. Public Health Nutr. 2012;16(4):653-8.

45. Galeone C, Pelucchi C, Talamini R, Levi F, Bosetti C, Negri E, Franceschi S, La Vecchia C. Role of fried foods and oral/pharyngeal and oesophageal cancers. Br J Cancer. 2005;92:2065-9.

46. Ministry of Education. Conducting school canteens and taking food during school time. In: MoES L, editor. . Colombo: Ministry of Education; 2011.

47. Lagergren J, Bergström R, Nyrén O. Association between body mass and adenocarcinoma of the esophagus and gastric cardia. Ann Intern Med. 1999;130(11):883-90.

48. Kubo A, Corley DA. Body mass index and adenocarcinomas of the esophagus or gastric cardia: a systematic review and meta-analysis. Cancer Epidemiol Biomark Prev. 2006;15(5):872-8.

49. Ibiebele TI, Taylor AR, Whiteman DC, van der Pols JC, Austrailian cancer study. Eating habits and risk of oesophageal cancers: a population-based case-control study. Cancer Causes Control. 2010;21(9):1475-84.

50. Tramacere I, La Vecchia C, Negri E. Tobacco smoking and esophageal and gastric cardia adenocarcinoma: a meta-analysis. Epidemiology. 2011;22(3):344-9.

51. Bathija GV, Itagimath SR, Bant D, Lokhare L. Study on socio-demographic and associated risk factors for Oesophageal Cancer in Karnataka Institute of Medical Sciences Hospital, Hubli, Karnataka. Scholars Journal of Applied Medical Sciences. 2014;2(2C):706-10.

52. Brouwers $M$, Kho ME, Browman GP, et al. on behalf of the AGREE next steps consortium: AGREE II: advancing guideline development, reporting and evaluation in healthcare. Can Med Assoc J. 2010;182(18):E839-42.

53. Lee WJ, Lijinsky W, Heineman EF, Markin RS, Weisenburger DD, Ward MH. Agricultural pesticide use and adenocarcinomas of the stomach and oesophagus. Occuptional \& Environmental Medicine. 2004;61:743-9.

54. Golozar A, Etemadi A, Kamangar F, Malekshah AF, Islami F, Nasrollahzadeh D, Abedi-Ardekani B, Khoshnia M, Pourshams A, Semnani S, et al. Food preparation methods, drinking water source, and esophageal squamous cell carcinoma in the high-risk area of Golestan, Northeast Iran. Eur J Cancer Prev. 2016;25(2):123-9.

55. WHO. Water Sanitation Health. In: Managing water in the home: Accelerated health gains from improved water supply. n.d.

56. Dissanayake CB, Senaratne A, Rupasinghe MS. The heavy metal pollution in Kelani River in Sri Lanka. Aqua. 1985;2:79-88.

57. Risk and causes of oesophageal cancer. https://www.cancerresearchuk.org/ about-cancer/oesophageal-cancer.

58. Ji J, Hemminki K. Familial risk for esophageal Cancer: an updated epidemiologic study from Sweden. Clin Gastroenterol Hepatol. 2006;4:840-5.

59. Lagergren J, Ye W, Lindgren A, Nyrén O. Food, Cancer Epidemiology. Biomarkers and Prevention. 2000;9:757.

60. Bird-Lieberman EL, Fitzgerald RC. Early diagnosis of oesophageal cancer. Br J Cancer. 2009;101:1-6.

61. Department of Census and Statistics, editor. Census of population and housing, Sri Lanka-2012. Colombo: Department of Census and Statistics SL; 2012.

62. Drinking levels defined. http://www.niaaa.nih.gov/alcohol-health/overviewalcohol-consumption/moderate-binge-drinking.
63. National institute on alcohol abuse and alcoholism (NIAAA). NIAAA news letter. In: NIAAA News letter, vol. 3. United States: US department of health and human services; 2004.

64. Liyanapathirana A. Prevalence of coronary heart disease (CHD) and selected risk factors of $\mathrm{CHD}$, utilization, perceived access, health system responsiveness and household costs of ambulatory health care among people aged 30-64 years in the district of Gampaha. Post Graduate Institute of Medicine, University of Colombo. 2014.

65. Friedenreich CM, Courneya KS, Bryant HE. The lifetime total physical activity questionnaire: development and reliability. Med Sci Sports Exerc. 1998;30(2): 266-74.

66. US Centers for Disease Control and Prevention. Health behaviors of adults: United States, 2005-2007. In: Vital and Health Statistics, vol. 80; 2010.
Ready to submit your research? Choose BMC and benefit from:

- fast, convenient online submission

- thorough peer review by experienced researchers in your field

- rapid publication on acceptance

- support for research data, including large and complex data types

- gold Open Access which fosters wider collaboration and increased citations

- maximum visibility for your research: over $100 \mathrm{M}$ website views per year

At BMC, research is always in progress.

Learn more biomedcentral.com/submissions 